\title{
Concepts of legitimacy within the context of adaptive water management strategies
}

\author{
Mary Gearey and Paul Jeffrey
}

Centre for Water Science, Cranfield University, Bedfordshire, MK43 0AL, UK

\begin{abstract}
This paper argues that to prevent or lessen the impact of episodic water stress within modern political economies, harnessing and tailoring emerging modes of legitimacy will play a crucial role in formulating pragmatic, solution-focused policy. In setting out a case for this position, we analyse the role which existing and novel modes of legitimacy play in shaping the boundaries and opportunity spaces for policy tool development. Central to the arguments outlined is a rethinking of the concept and practise of 'legitimacy' to include informal relationships between actors and amongst institutions. Legitimacy's re-evaluation is pertinent as existing demand management elements of Integrated Water Resource Management (IWRM) become increasingly ineffectual in the face of escalating water stress. This paper's focus is on the interface between IWRM and socio-political values associated with potable water. This leads us to concentrate almost exclusively on public water supply issues within developed countries. It is argued that adaptive water management techniques will play a key role in policy development; but only if strategies recognise the need to engage with the diverse range of legitimacy models which typify late-industrial societies. The paper reviews theories of state action, civic participation and sovereignty to explore, through the use of case studies, what types of legitimacy models, and what types of policy to enact these models, could be used to support strategies to alleviate water stress.
\end{abstract}

Keywords: Legitimacy; Water stress; Public water supply; Adaptive management; IWRM

\section{Introduction}

This paper argues that the role of legitimacy is pivotal in the development of adaptive water management strategies. In recent years, the growing phenomena of water stress ${ }^{1}$ has revealed a limitation in the ability of the Integrated Water Resources Management (IWRM) discourse to galvanise action and effect solutions to complex social, economic, political and environmental problems. The paper explores how the concept of legitimacy may assist in the development of an alternative focus for IWRM processes. As legitimacy operates within socio-political contexts this narrows the focus of the paper to address water management strategies that deal with public water supply and, to some extent, environmental services. In other words the focus lies within 'blue' water resources rather than 'green' water resources (Falkenmark and Rockstrom, 2004). Although IWRM issues connected with agriculture, and in 
particular irrigation, are challenging, they are not covered by the contribution presented below.

The paper is divided into five sections. Section 1 is the introduction. Section 2 outlines how a 'flattened' concept of legitimacy reflects the reality of post-industrial societies. This perspective is then contextualised in the following section through the use of three case studies which lead us on to a discussion of how legitimacy can enhance adaptivity in water management. Finally, our conclusions outline a set of research gaps and reflect on the desirability of manipulating legitimacy debates to support adaptive management approaches.

Any approach to the problems experienced by IWRM must begin by understanding the issue of water stress. Water stress is a complex and emerging phenomenon in natural resources management. The causes of water stress are not simple to categorise and include environmental, economic and social triggers. Water stress events can be episodic or stochastic and differ in their length and degree of severity. Whilst each event can be understood as a unique conglomeration of contributory factors, they can also be emblematic of a progressive decline in natural resilience, social cohesiveness or both. Ohlsson (1999) has defined natural water shortage in semi-arid and arid areas as 'first-order scarcity'; put simply, not enough available water per head of population. A society's inability to adequately conserve, protect or utilise its water resources to meet needs is classed as 'second order scarcity'.

Theoretically, developed countries should be able to overcome first order scarcity through technical and financial capabilities However, this paper asserts that it is IWRM's continued focus on demand management strategies that is hampering the development of policy tools to tackle water stress. It is argued that as many developed societies may well need to adjust to increasingly frequent episodes of water stress (Arnell, 1998) this will necessitate a step on from the demand management focus of IWRM to developing water management strategies founded on concepts of adaptive capacity. ${ }^{2}$

Adaptive management has been described as 'learning-by-doing' and promulgates an iterative three-stage continuum of action, monitoring and adaptation. In each of these three stages, alternative hypotheses are used to evaluate the successes of any decision making process (Norton and Steinemann, 2001). These adaptive strategies require room to learn through experimentation and failure. Pertinent to these novel techniques for IWRM is an appreciation that solutions may lie outside of the water sector and within the domain of the non-expert. Although IWRM theory is underpinned by the idea of community management of water resources, the difference between IWRM and adaptive management lies in the execution of theory in practise. If water stress events are reflections of a wider macro level problem set, solutions may lie outside of the IWRM domain entirely. Indeed, we may need to look to adaptive management to create the space in which IWRM theory can manifest itself into a policy provider which is truly integrative.

The theoretical framework that underpins adaptive approaches as a natural resource management strategy are well established (e.g. Holling, 1978 and Gunderson and Holling, 2002). The concept of legitimacy, explored in more detail in the following section, describes the formal and informal ways in which processes, policies, 
structures and agents are validated and consequently empowered. As a conceptual device, legitimacy has roots in legal theory, but has also been used by social scientists to explain how norms are generated, how power operates and how institutions and regimes remain stable over time (Beetham, 1991). Though legitimacy is usually employed to explain relationships of representation, our argument adopts a broader reading of the term which sees legitimacy as a facet of good governance..$^{3}$

Theories of good governance suggest criteria for evaluating legitimacy. Many such theories distinguish between the level of 'input legitimacy' (the issue of how decisions are taken) and 'output legitimacy' (whether a goal has been successfully achieved) (Scharpf, 1999). However, we need to push this model further if we are to fully understand how legitimacy becomes embedded in a cultural context. This anchoring of legitimacy has been described by Schimmelfennig (1996) as 'social legitimacy'; such social or popular legitimacy is paramount to securing successful input and output legitimacy.

Legitimacy is re-sited then, away from formal institutions and actors and is relocated within a network of relationships that are constantly in flux. Thus, achieving policy goals, for example, must take into account the economic, social and political networks which legitimate or delegitimate policies, practises and people. Put another way, legitimacy is discursively determined; it is constantly subject to review, assessment and revaluation. This makes it a potentially volatile attribute. Examples of scandalised politicians, ousted Chief Executives, and reformatted policy in response public outcry, all demonstrate legitimacy's mobility and fragility. Essentially it also underscores how far legitimacy resides within common debate and remains an iterative, tangible social concept. If a process, person or policy is viewed as socially legitimate, then there is likely to be a higher value placed on input legitimacy; conversely an absence of social legitimacy may compromise or dilute possible option spaces ${ }^{4}$ for outputs. Legitimacy is gained then through a cycle of achievement which is self-reinforcing. When formal policy implementation processes attempt to demand validation without achievement then there is a divide between formal authority and popular support-this is known as the 'legitimacy gap'.

To place this agenda within a wider consideration of water resources planning and management, we would note that historically, whilst formal methods of water resources planning (e.g. Cost-Benefit, Multi-Objective or Market-Based approaches) have generated useful technical tools for tractable problem sets, they fail to address the issue of policy implementation or deployment. Identification of a least cost, or best practicable option is only half a solution. Effecting policy options where we recognise the operating environment to be complex, multi-actor, and perhaps unstable is only partially eased by an understanding of trade-offs. Other social and political factors need to be manipulated if selected policy mechanisms are to be successfully promoted and adopted. We need to evaluate how far narrowing the 'legitimacy gap' could play a role in shaping the option spaces for policy tool development and deployment within the context of adaptive water management. Our argument will develop in the next section.

\section{Concepts of legitimacy}


Legitimacy is a key concept in political theory, one which explores and explains relationships between actors and institutions in which authority, or power, has been delegated. The prevalent models of legitimacy in social, legal and political theory tend to see it as a model of sovereignty i.e as being formally enshrined in codes and practises in which power is delegated..$^{\frac{5}{}}$ This is useful in that it can explain the way in which both government and policy are justified. Yet sovereignty as a macro model of legitimacy is obstructive if it prevents us, as discussed above, from appreciating that legitimacy operates as a network that brings together both institutions and actors in what could be visualised as horizontal inter-linkings, rather than a vertical 'top-down' hierarchy. Put simply, it might be suggested that legitimacy as sovereignty is visible whilst legitimacy as a network is invisible. For example, the legitimacy of the English and Welsh water companies to manage public water supplies is enshrined within the 1989 Water Act. Yet the Internal Drainage Boards (IDBs) which provide drainage services to many parts of the country, and are co-operatives run by landowners remain relatively unknown. We would suggest that IWRM at present addresses the visible, yet it has failed to articulate strategies to address the invisible. Without both, IWRM does not provide a robust platform for responding to water stress challenges. Using the above examples, IWRM processes need to also include insights and participation from grassroots organisations such as the IDBs to gain embedded legitimacy.

There is then an obvious need to both broaden and deepen the remit of the IWRM discourse. Recognising that water stress cannot be alleviated by demand management alone and that concepts such as international water markets, 'virtual water' (Allan, 1997) and radical technological innovation may become mainstream, water management moves from the realm of experts to inhabit a communal space-both externally in terms of efficient water use practises in the garden and use of water efficient technologies and internalised through emerging norms such as a willingness to use recycled water or varying qualities of water. Foucault's work (see Foucault, 1970 and Foucault, 1972), which posits that in the post-industrial era boundaries and ideas of sovereign territory and sovereign resources begin to dissolve, illustrates the new terrain facing IWRM. IWRM becomes truly integrated by entering every domain of social relationships. The formal location or arena in which legitimacy is negotiated thereby becomes fragmented. Yet it is timely here to remember that the pace and nature of change is guided by a very powerful dynamic - it will be the developed countries that initiate the change and determine the scope. How far water-scarce developing countries will have the ability to fit into these changing global relationships is yet to be seen and outside the remit of this paper.

We cannot talk of citizenship without discussing water rights, or, more pertinently, rights to water. Whilst a review of rights to water is a discipline in itself there are a few key points relevant to adaptive management approaches. Firstly, a 'right to water' is a concept which operates within specific political economies. This is because a right is a legal concept which can only operate within the rule of law. Yet it is recognised by international institutions, such as the UNEP and WHO, that access to safe and reliable water is a human right as decreed by Article 25 of the Universal Declaration of Human Rights (1948) because it is essential to maintaining an adequate standard of living. We have then not a right to water but a right to a guaranteed standard of living which cannot be attained without access to a safe and reliable water source. Much work has been undertaken since 1948 to declare water in itself as a human right; not just as an adjunct of standards of living indicators. For example, the 
1994 Water Act of the Republic of South Africa strives to develop a supraconstituency in which the regional, racial and economic divides of old South Africa are abolished. The Water Act demands as much: 'These guiding principles recognise the basic human needs of present and future generations, the need to protect water resources, the need to share some water resources with other countries, the need to promote social and economic development through the use of water and the need to establish suitable institutions in order to achieve the purpose of the Act' (RSA National Water Act 1998:14).

What is enshrined here is a vision of freshwater as inseparable both from citizen's rights and the long term welfare of the nation. In terms of adaptive management it is this ethos of a unified approach to freshwater management which is crucial. The South African example demonstrates that rebuilding legitimacy between state and citizen through inclusive water policy making has real potential. The following three case studies examine how different modes of policy making can also have a positive impact on legitimacy building.

\section{3. 'The Legitimacy Gap': three case studies}

This section presents three short case studies that highlight different approaches to legitimacy building. The first, the privatisation of the English and Welsh water sector in 1989 details the transition from public to privately owned water supply networks. The second, reviewing a public water authority's response to a drought event in Australia, examines the rationale of using price as the main tool of demand management progressing to a more disciplinarian set of policy instruments. The final example, which reports a water contamination incident in the small town of Walkerton, Canada, explores the issue of legitimacy in the context of local/national dialogues. Each example is used to illustrate how the cultural, economic and political make-up of a different set of circumstances will shape the option space for the successful implementation of policy instruments and therefore determine a relevant legitimacy agenda.

\subsection{Case study 1: the privatisation of the English and Welsh water sector}

Privatisation of water in the UK typifies neo-liberal economic policy approaches (Browning, 2000). In England and Wales the privatisation of the water sector led to a full scales divestiture of assets and was far more radical than in other countries where there has been a gradation between full public ownership options and total privatisation of service and assets (Winpenny, 1994). The intended aim of the privatisation process in England and Wales was to increase investment levels and reduce costs. It was also hoped that privatisation would improve efficiency, service standards and technical capacity (Summerton, 1998 and Richardson et al., 1992). We will suggest, however, that despite the transformation of the sector, there remains a worrying legitimacy gap.

If one studies the process of English and Welsh privatisation, one finds that great regard was given to making sure changes were regarded as legitimate. Richardson et al. (1992) detail the courtship of the water boards and local government by central government in order to slowly convince them that not only was wholesale change necessary, but also achievable. The success of the privatisation process also relied on 
developing an industry which appeared dynamic; water companies appearing as commercial 'players' in order to attract foreign direct investment. The most challenging aspect of privatisation, though, was the goal of persuading water users to accept water privatisation and to spur them to become shareholders. This was particularly difficult as opinion polls of the time revealed between $70 \%$ and $80 \%$ of the population were opposed to the privatisation process (Ernst, 1994), as it was perceived as a selling off of a national heritage.

Perhaps the very achievement of water privatisation shows that those in charge of marketing strategies did have an appreciation of legitimacy issues, although, as we will show, there remain concerns as to whether the divestiture model was the most appropriate. Given the initial hostility of popular opinion ${ }^{6}$ to the privatisation process it is useful to isolate three strategies which might explain why the new water management structure was accepted.

Firstly, the rapidity of change left little chance for criticism. In just 18 months, from the Water Act's ratification in July 1989 to the sale of the Water Holding Companies in December 1989, the sector was transformed in terms of regulatory structure, financing and ownership. Secondly, the mode of change was also significant. It embraced the economic mood of the decade. Privatisation was pitched as a means for everyone to become part of a share-owning democracy. The third factor that led to the perception of privatisation as a success was the relative stability of prices and continuity of the water holding companies post-privatisation (the changes seemed to be in name only). This lessened the upheaval. In summary, it could be suggested that the limited consultation process coupled with exceptionally strong state endorsement can be seen as the engine behind the seemingly successful re-configuration of the water industry.

However, the ability of the water sector to transform and continue to thrive does not mean that the legitimacy agenda has caught up. The most convincing explanation for the apparent ease of transformation was the monopolistic nature of the industrycustomers could not simply switch providers or refuse to consume. There are other indications that privatisation has not been accepted. From a disregard of water use limitations (Haughton, 1998), to non-payment of bills by consumers who know that they cannot be easily disconnected, and a general disgruntlement with private ownership of the sector (MORI, 2002) there has not been total public support. Indeed, Bakker describes the disjunctures brought about by privatisation as the 'primary source of the legitimacy crisis of the privatised water industry' (Bakker, 2001. p157). The example of the English and Welsh water industry privatisation suggests that what was meant to be a reform directed towards efficiency of management remains a politically contentious act.

\subsection{Case study 2: the Sydney Water Authority and the 1999 drought}

Our second example focuses on policy tool adaptation as a specific response to acute water stress during a drought period in Australia. However, many factors contributing to the drought, including poor river quality, an ageing infrastructure and rapid population growth are symptomatic of IWRM challenges facing Australia. Specifically, this case study shows that unpopular policy mechanisms can be successful if high profile education campaigns are used to explain the reasons behind 
the policy, thereby legitimating action. Sydney Water, a private water supply company regulated by the government, has been experimenting since 1999 with a range of demand management programmes as part of a national programme of policies to counter increasing water stress. These range from incentives (e.g. cash back for installing water efficient appliances), to new standards (such as labelling of all water using equipment to indicate efficiency levels) and outright water use restrictions. For the purposes of this study we will focus on the restrictive measures.

In November 2002, as an adaptive response to an ongoing drought period, the company initially introduced voluntary water restrictions to the city of Sydney and its surrounding suburbs. This new policy instrument was focused at the micro scale. It restricted garden watering from 8 am until $8 \mathrm{pm}$ (except for the use of recycled water and drip irrigation) and the hosing of any hard surfaces such as drives and cars at any time. Working in collaboration with the Sydney Catchment Authority (responsible for the bulk water resource) and drafted by the New South Wales minister for Energy and Utilities, these restrictions only applied to households and were entirely voluntary.

Although the government and the water company used the term 'restriction', no mention was made of possible penalties for refusal to comply. Instead, the language (disseminated through the media in the forms of press releases, fact sheets and interviews) focused on citizen responsibility and a community shaming approach. Neighbours were invited by the local press to inform the company of contraventions to the restrictions. The local Catchment Authority also requested the names and addresses of those not complying with the restrictions, principally so that deviators could be sent water saving advice pamphlets. That the restrictions focused upon external water use, and therefore not to private but to public utility, signals strongly that the resolution of water shortage was being presented as a community responsibility. Press releases detailed restricted practises and contained other pieces of data intended for public consumption. Attention was drawn to statistics concerning groundwater and reservoir levels as a percentage of normal capacity. A "hit list" of non-contentious ways to conserve water around the home was also published.

In terms of legitimacy issues, these publications contained a pervasive theme: 'us against nature'; a more exaggerated approach than the mainstream national IWRM approach which advocates collective (i.e. municipal and individual) approach to demand management. The point was to create public ownership of the problem, and to unite three different spheres-market, regulators and consumers against the drought event. The continued severity of the drought has lead to these semi-voluntary restrictions becoming upgraded to 'level 3'. Garden hosing is now limited to early morning or evening on Wednesdays and Sundays only. Car washing with a hose is forbidden and permits are required for swimming pools over a certain size. Sydney Water officers now patrol suburban areas and can issue on-the-spot fines of \$220 Australian dollars for contravention of the restrictions. In tandem the Sydney Water Authority has also announced in July 2005 plans to develop a $£ 1.5$ billion desalination plant. This will provide Sydney with 500 million litres of potable water a day. Anecdotal evidence gathered by the local media suggests that these twin developments have been accepted as necessary; though hostility remains regarding the siting of the desalination plant. 
It can be suggested that by introducing voluntary restrictions prior to state enforced penalties the public are more prone to accepting the need to develop more adaptive water management strategies. The legitimacy terrain has been gradually sculpted through information campaigns and readily accessible scientific data. Clearly scaling up policies in response to highly visible falling reservoir levels has also provided the IWRM agenda with legitimacy.

The three characteristics of the handling of the drought in Sydney, namely governance, leadership and information management, can be seen in their wider context of galvanising Australian IWRM and overcoming weaknesses regarding scale, decision making and accessibility that have slowed its national adoption. The success of the Sydney Water Authority approaches has seen residential water use dropping by 12\% since September 2003 (Turner et al., 2005). In terms of the long term evolution of a consolidated IWRM process in Australia, the Sydney case study illustrates a successful method of obtaining 'buy in' from domestic and individual consumers and developing a cohesive plan of action. The high 'output' legitimacy created by the Sydney Water Authority taking an incremental approach has created a feedback loop leading to strong 'input' legitimacy for the water management institutions.

\subsection{Case study 3: the Walkerton incident, Ontario, Canada. May 2000}

This well reported case study (see, for example, Snider, 2004) is a prime example of how a high level of input legitimacy within a local community leads to adaptive, solution-focused responses despite negative events. In this example, the small community of Walkerton was affected by a sudden, unexpected outbreak of Escherichia coli contamination to their local water supply (O'Connor, 2002). Confirmation of the contamination came not from the local public water supplier but from a general practitioner who was alarmed by a sudden rise in illness amongst the very young and old within this small community. Of special interest is that the dissemination of this public health event came not from the community itself seeking explanations, but from the local and then national media who lobbied hard, challenging the public water company to explain its inaction. This media interest is contextualised by the former Socialist government's stance to include the environmental lobby in policy making. Canada's IWRM model includes municipal water companies underscored by a hands-off approach to central management. The media frenzy can therefore be seen as a tool to argue against ministerial budget cuts. This case study notably demonstrates the flexibility that personal responsibility and reliability can foster. As this was a small community the head of the water authority was a high-profile community member and known to most. As the news of the contamination reached the national press, the community responded by exploiting social cohesion and common interest, reacting in a unified and dignified manner to the problem. The implicated water company employees were not made scapegoats; rather the whole community were interested in finding the cause of the problem and ensuring it was not repeated. Instead the management problem was treated as a tragedy which nobody wanted to happen, with the whole town rallying in support of those residents associated with the water company against the aggressive interference of the media.

This case study reveals the absence of a legitimacy gap, despite the unenviable circumstances. Whilst this could potentially be dismissed as a normal facet of small 
town life in such a litigious age, events on this scale (hundreds were made ill for up to 6 months and seven people died as a result of the contamination), it would be unhelpful to look into other factors which have created this supportive network. Using legitimacy as a tool to explain the reaction to such an event, we can say that the high level of input legitimacy evident in all public figures encountered within the example leads to a reflexive, mutually supportive community. The indirect blame was accepted as the result of central budget cuts. There is no evidence of a gap between consumers and water authority, as water authority staff are also recognised as consumers too. We could argue that it is the open accessible relationship between the two which has created this supportive legitimising relationship. It also reflects the largely rural nature of potable water provision in Canada. Provincial IWRM approaches are more meaningful at community level than federal policies. The case study subsequently provides us with a method to improve input legitimacy in IWRM strategies by investing resources in the contact time between water company and user. Would investing money in building community relations or developing community teams negate the need for undesirable, unpopular or unsuccessful coercive policies?

Another outcome from the Walkerton tragedy was the response of the community to suggestions that water experts had let them down. The consensus seemed to be that the problem stemmed from experts being asked to rely on technology rather than their training and expertise and that technology had also reduced their numbers, leading to an over-reliance on technology to provide safety. What the community were arguing then was to let the 'local' back into water guardianship. Again, this returns us to Schimmelfennig concept of social legitimacy; that subsidiary level expertise and local knowledge would always balance social and environmental needs far better than macro based planning. In terms of our adaptive management philosophy we can say from this example that the legitimacy gap is obliterated when people are privileged over technology. This has been addressed at a provincial level by the establishment in October 2004 of the 'Walkerton Clean Water Centre' to train staff in managing small and remote water systems. There is recognition then in terms of long term IWRM for Canada that its size and scale mean that localised, specific responses are more meaningful than adopting broad-brush macro policies. Again, this case study illustrates an adaptive approach in response to shifting legitimacy concerns.

In all three of the examples described above we see macro and micro level changes to the governance of the water resource; multiple stakeholder involvement, and temporal lags between policy mechanism deployment and the reconfiguration of the legitimacy landscape (Table 1).

-Table 1.

Case study evidence for impacts on the legitimacy terrain 


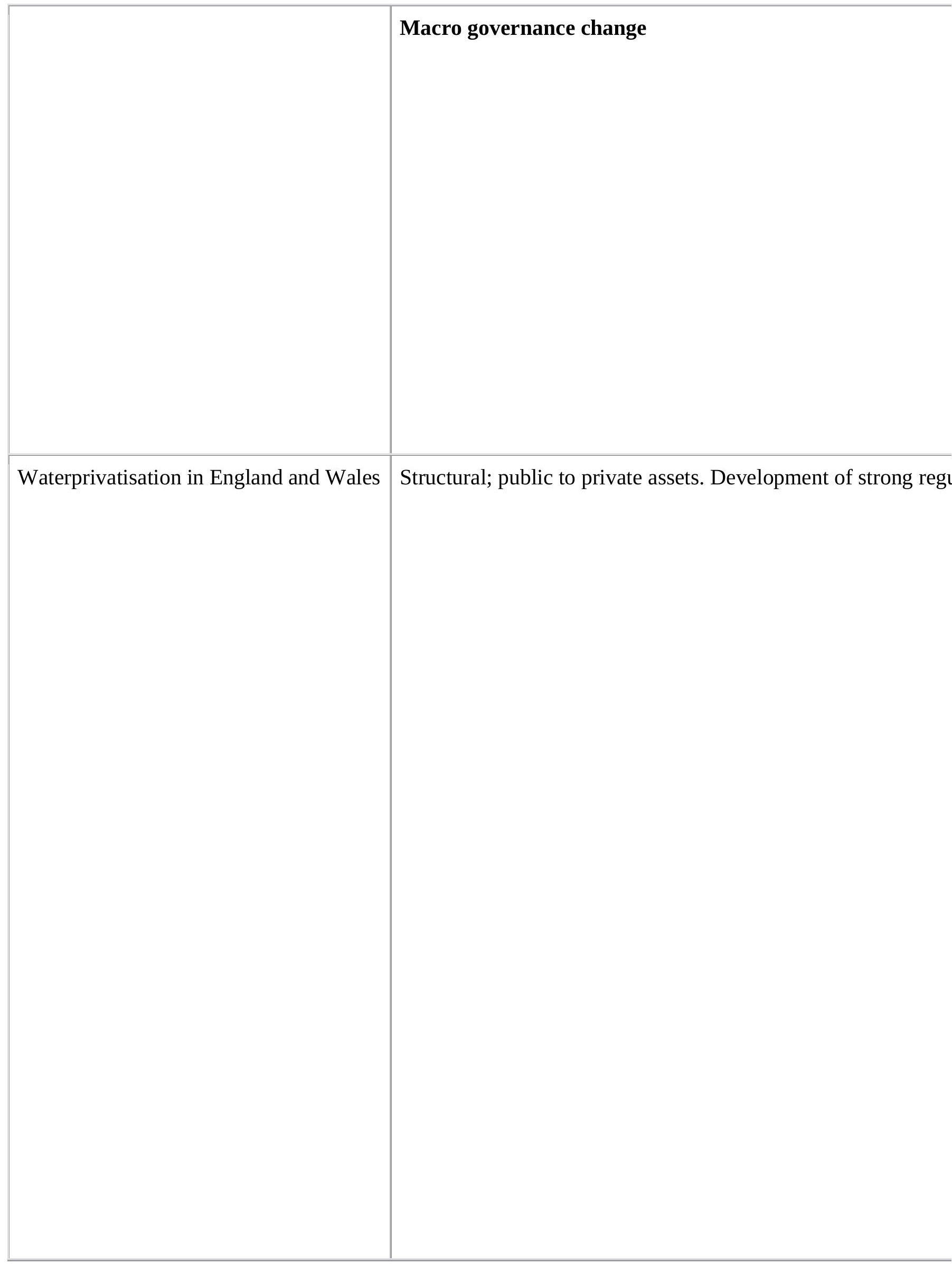


Macro governance change 
Macro governance change 


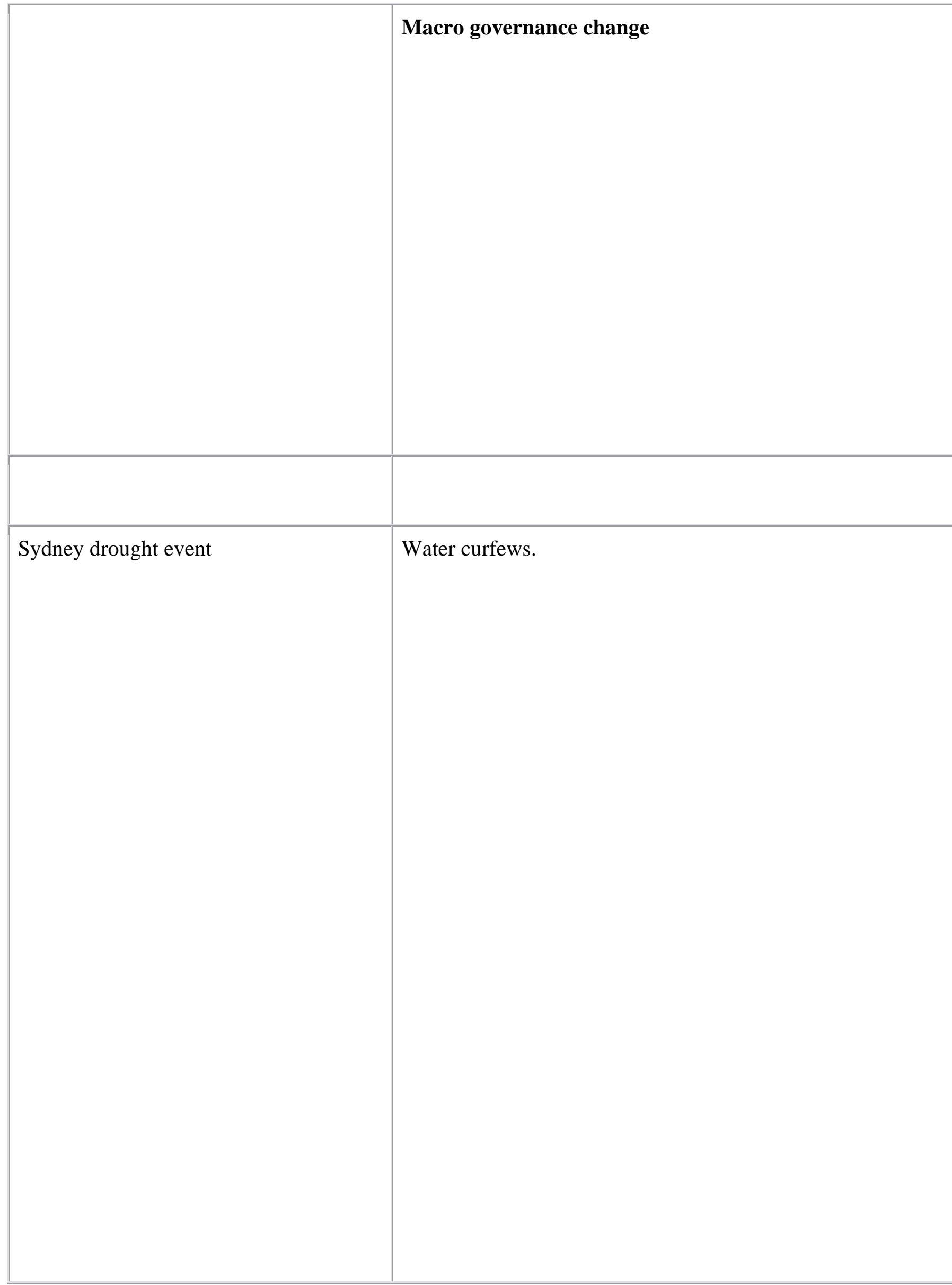


Macro governance change 


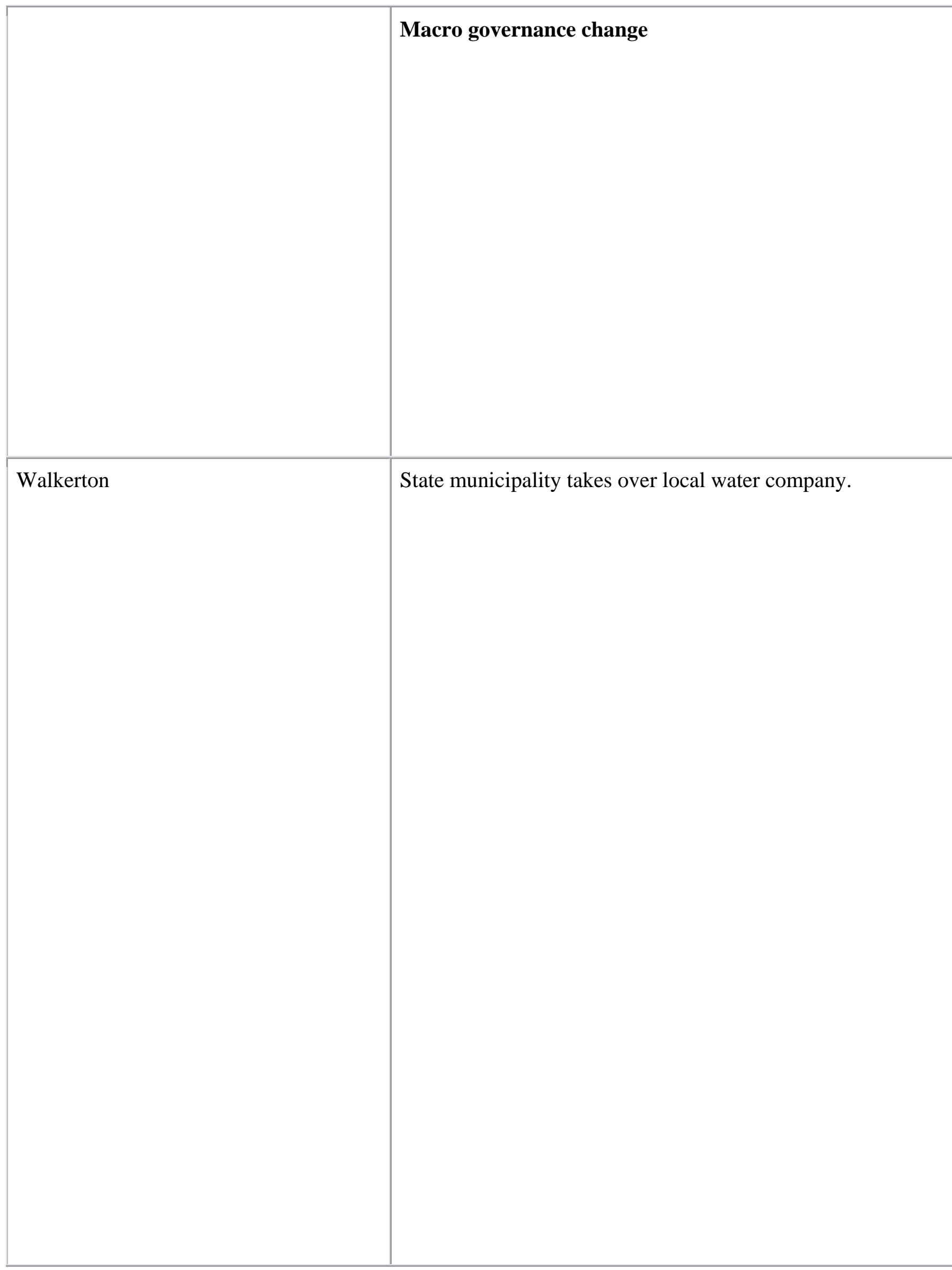


Macro governance change 


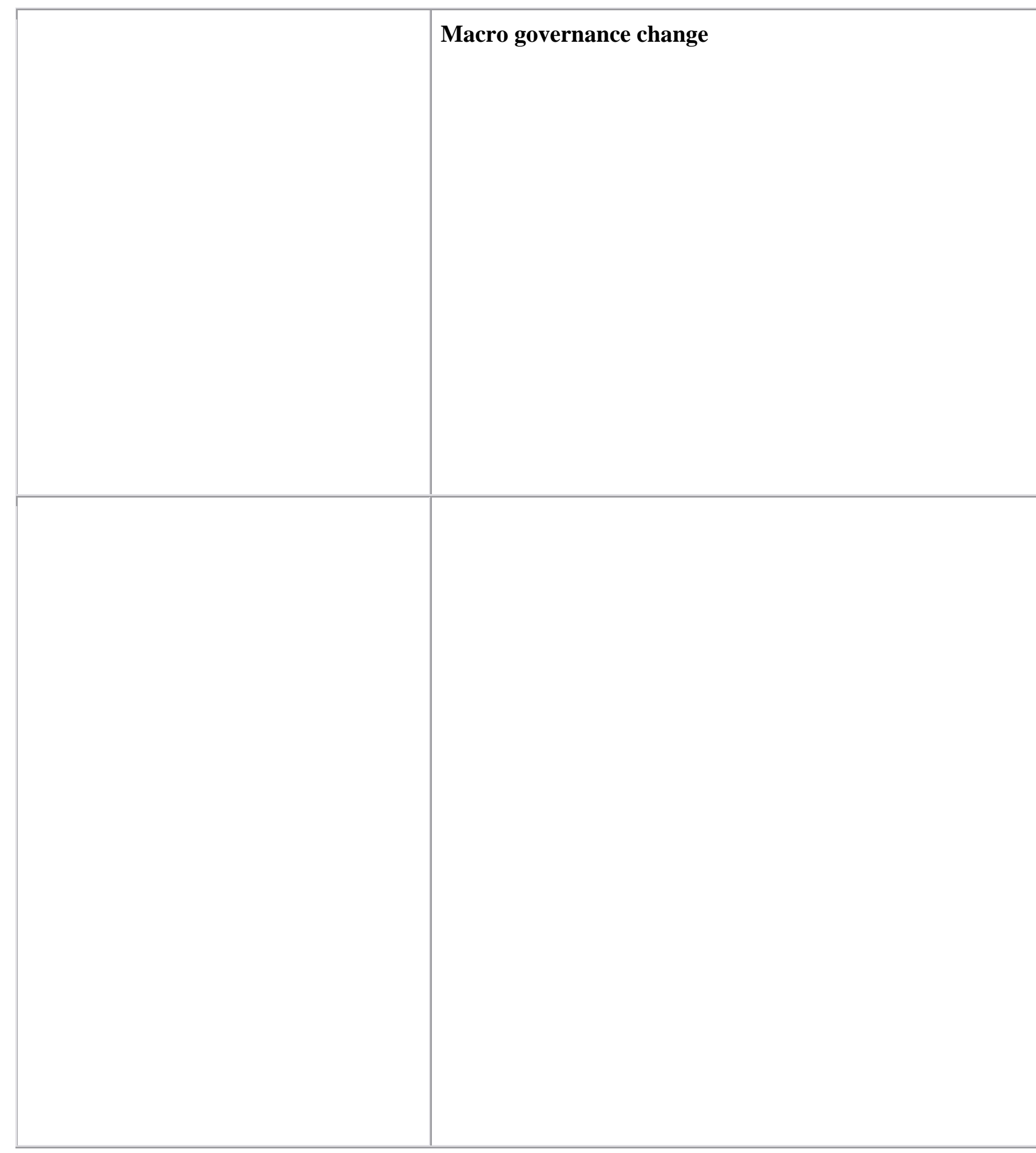

Common to all three examples is the reconfiguration of multiple legitimacy terrains which involve different actors at different points in the process. Also common are the selective perspectives which are offered. In the case of the privatisation process, consumers were offered a stake through share options whilst having no route to disagree with the macro changes involved. In the Sydney case neighbours become 
water policemen and the drought event is provided with a scientific explanation rather than general mis-consumption by users, leading to a recognition of the need to reconfigure IWRM approaches in response to new water stress drivers. The Walkerton example illustrates how even high levels of embedded legitimacy can be quickly eroded if the community has no way of rationally dealing with problems of locally induced risk in an age when safety is generally safeguarded by policy. All three examples show in different ways the enormous difficulties of implementing IWRM policy changes and the gap between the policy goal and the means to successfully operationalise adaptive policy tools. However, can we draw any wider lessons about the structures of legitimacy from these illustrative instances?

\section{Legitimacy's role within adaptive IWRM strategies}

If we accept that managing the water environment is beyond hydraulic engineering alone and, furthermore, if we accept that demand management can only ameliorate water stress to an extent, then we can start to focus on what kinds of strategies an approach founded on adaptive capacity will engender. Table 2 suggests examples of characteristic legitimacy agendas for three types of policy instrument; supply led, demand led or adaptive. Whilst adaptive responses to water stress will be self evident in some areas (for example greater water use efficiency in the home and the use of water hardy crops in agriculture) it is in the longer term impacts on society where the legitimacy gap will be most acutely felt. Water stress may affect future food security, economic security, international trade relations, it may dictate the jobs we do, where we live and how we live. On a fundamental level, increasing water stress could raise moral and ethical questions as to how we balance, replace, or abandon, individual freedoms and community approaches to our use of water resources. Addressing the structural shifts that developed societies will need to undertake is not something that can be undertaken by one sector, or during one term of government.

-Table 2.

Examples of changing legitimacy agendas across modes of water management

\begin{tabular}{|l|l|}
\hline & Characteristic legitimacy agendas \\
\hline Supply led strategies & $\bullet$ Needs of society supercede needs of natural environment. \\
\hline & $\bullet$ Targets of universal supply mean that urban customers cross-subsidise rural cus \\
\hline & $\bullet$ Large (volumetric) water users have a greater input into policy making than ind \\
\hline Demand led strategies & $\bullet$ Full cost recovery principle moves water from a solely social to a principally ec \\
\hline & $\bullet$ Water pricing to deter use penalises those on a lower income. \\
\hline Adaptive strategies & • Solutions to food security may lie outside of national boundaries (virtual water) \\
\hline & $\bullet$ Social justice and social equity to be included in the pricing of, and access to, $\mathrm{n}$ \\
\hline
\end{tabular}


For adaptive management to flourish within IWRM it needs to become an integral part of the way we value and use freshwater resources, in the same way that concepts like 'individual liberty' or 'democracy' become, over time, accepted and legitimised as intractable societal goals.

IWRM policies must enable change to occur at a pace that will be accepted; but is this possible? Social relations with water as a commodity are vastly different from more mundane, pedestrian market products. Water has culturally specific roles in society (Strang, 2001). Changing these norms at a progressive pace may not be fast enough to cope with escalating water stress.

The enhancement of adaptive capacity involves multilayered and multi-temporal policy tool development which will involve coercive, remunerative and pliable policies. As the exploitation of adaptive capacity necessarily involves sectoral shifts, the meta problem is that of co-ordinating these changes. Although we can see that some policy mechanisms can change behaviour and attitudes in certain key areas, whether individual states itself have the capacity to provide an integrated response to such wide ranging questions is another matter.

One of the key areas that need to be tackled through IWRM strategies and processes, is the development and strengthening of concepts of legitimacy in relation to water, between actors and amongst institutions. Given a scenario of increasing global susceptibility to water stress, dynamics will necessarily change, from formal legitimate relationships between water supplier and water consumer to enhanced relationships of guardianship between citizens and the resource. We can see the potential of these changing relationships to foster dynamic and emerging forms of cosupporting legitimacy between community groups and policy makers moving outwards onto the global arena to initiate trans-boundary inter-state relationships to mitigate conflict situations through the further development of international legitimacy.

Deepening structures, processes and systems of legitimacy then will prompt planners and policy makers to recognise both formal modes of legitimacy and the informal devices through which ideas and practises are negotiated. We recognise the difficulties which policy makers face when trying to co-ordinate the different expectations, operations and actors that will need to be factored in to an adaptive capacity framework. The landscape of legitimacy will likely take longer to reconfigure than that of policy mechanisms; our concern is that legitimacy will lag so far behind mechanism change as to severely compromise the effectiveness of each policy option.

\section{Conclusions}


This paper has argued that the role of legitimacy is pivotal in the development of adaptive water management strategies. This is not to assume that there is one type of legitimacy; rather we can isolate that developing (i) social or (ii) coalitional legitimacy will support adaptive strategies far more effectively than current experiences where there is a legitimacy gap. Future IWRM success will be dependent on a holistic appraisal of water's role in society. By recreating a 'social' contract between water consumer and water guardians, legitimacy widens the opportunity space available to planners and policy makers.

Our portrayal of IWRM as being in need of a revised appreciation of the role of implementation support tools (in this case legitimacy) reflects wider censure of the extent to which IWRM theory has been realised as practice: 'There is still a long way to go to achieve a common understanding of IWRM and to develop and re?ne approaches for its successful implementation.' (Jonker, 2002, p. 719). Perhaps the most insightful observation regarding this gap comes from a book review which, although published over a decade ago, still rings true today. The review draws attention to a shared 'basic faith in the concept and aims of integrated management' but also points out that 'despite some achievements and extraordinary capital investment, national governments have by and large failed to sustain truly integrative programmes.' (Westcoat, 1992). Other commentaries have pointed out that IWRM is immature as a management tool. For example, 'IWRM has neither been unambiguously defined, nor has the question of how it is to be implemented been fully addressed. What has to be integrated and how is it best done? Can the broad principles of IWRM be operationalised in practice-and, if so, how?' (GWP-TAC, 2000). Contemporary concern over this lack of applied success is such that the United Nations Environment Programme was recently prompted to classify the conversion of the concepts of integrated water resources management into practice as "Unfinished Business” (IWA/UNEP, 2002).

Our thesis as presented in this text conjectures that, for policy makers, the task is in managing sectoral shifts equitably. This requires a subtle array of tariffs, quotas, reeducation, public participation and indirect taxes and other tools available to the state to enable a valuing of water as both a local and global resource. We are then left with a puzzling array of choices which seem to combine into a line of argument which champions social responsibility but recognises that this has to be developed by both hard tactics, an appreciation of monetary cost and reasoned debate. This integration (coordination plus assimilation) of policy mechanisms across space, time, sector, and social grouping will require new legitimacy dialogues which will themselves require fine tuning to match cultural and historical circumstances. Illegitimate solutions, particularly where there are significant pressures on resource availability, are likely to be unstable as a basis for resource governance and will undermine wider forms of social cohesion. The challenges which adaptive management goals generate are certainly formidable, but the perils of not embracing them may prove overwhelming.

\section{Acknowledgements}


The work on which this paper is based was financially supported by the European Commission under the AQUADAPT project—contract EVK1-CT-2001-00104. Our thanks also to Adam Gearey for constructive comments on early drafts of this paper.

\section{References}

Allan, 1997 A.J. Allan, Virtually no Water: the Middle East in 1997, EMAP Business International Limited, London (1997).

Arnell, 1998 N.W. Arnell, Climate change and water resources in Britain, Climate Change 3 (1998), pp. 83-110. Abstract-GEOBASE | Abstract-INSPEC | AbstractElsevier BIOBASE $\mid$ Order Document $\mid$ Full Text via CrossRef $\mid$ Abstract + $\underline{\text { References in Scopus } \mid \text { Cited By in Scopus }}$

Bakker, 2001 K. Bakker, Paying for water; water pricing and equity in England and Wales, Transactions of the Institute of British Geographers 26 (2001), pp. 143-164. Abstract-GEOBASE | Order Document | Abstract + References in Scopus | Cited By $\underline{\text { in Scopus }}$

Beetham, 1991 D. Beetham, The Legitimation of Power, Macmillan Education, Basingstoke (1991).

Browning, 2000 G. Browning, Contemporary liberalism. In: G. Browning and A. Halci, Editors, Understanding Contemporary Society: Theories of the Present, Sage, London (2000).

Dworkin, 1996 R. Dworkin, Freedom's Law, Harvard University Press, Cambridge (1996).

Ernst, 1994 J. Ernst, Whose Utility? The Social Impact of Public Utility Privatisation and Regulation in Britain, Open University Press, Buckingham (1994).

Falkenmark and Rockstrom, 2004 M. Falkenmark and J. Rockstrom, Balancing Water for Humans and Nature - the New Approach to Ecohydrology, Earthscan, London (2004).

Falkenmark and Widstrand, 1992 M. Falkenmark and C. Widstrand, Population and Water Resources: a Delicate Balance. Population Bulletin, Population Reference Bureau (1992).

Foucault, 1970 M. Foucault, The Order of Things, Tavistock, London (1970).

Foucault, 1972 M. Foucault, Archaeology of Knowledge and the Discourse of Language translated by Sheridan-Smith, A.M., Pantheon, New York (1972).

Global Water Partnership, 1996 Global Water Partnership, Effecting Water Governance, Technical Paper vol. 7 (1996) authors Rogers, P., and Hall, A.. 
Gunderson and Holling, 2002 L. Gunderson and C.S. Holling, Panarchy;

Understanding Transformations in Human and Natural Systems, Island Press,

Washington, DC (2002).

GWP-TAC (Global Water Partnership-Technical Advisory Committee), 2000 GWPTAC (Global Water Partnership-Technical Advisory Committee), Integrated Water Resources Management, TAC Background Paper vol. 4, GWP, Stockholm, Sweden (2000).

Haughton, 1998 G. Haughton, Private profits-public drought: the creation of a crisis in water management for West Yorkshire, Transactions of the Institute of British Geographers 23 (1998), pp. 419-433. Abstract-GEOBASE | Order Document | $\underline{\text { Abstract }+ \text { References in Scopus } \mid \text { Cited By in Scopus }}$

Herrington, 1998 P.R. Herrington, Analysing and forecasting peak demands on the public water supply, Journal of the Chartered Institution of Water and Environmental Management 12 (1998) (2), pp. 139-143. Abstract-Compendex | Abstract-GEOBASE $|\underline{\text { Abstract-FLUIDEX }}| \underline{\text { Abstract-EMBASE }}$ | Order Document $\mid \underline{\text { Abstract + References }}$ in Scopus $\mid$ Cited By in Scopus

Hobbes, 1996 T. Hobbes, Leviathan, Oxford University Press, New York (1996).

Holling, 1978 In: C.S. Holling, Editor, Adaptive Environmental Assessment and Management, John Wiley \& Sons, Chichester (1978).

IWA/UNEP, 2002 IWA/UNEP, 2002. Industry as a Partner for Sustainable Development: Water Management. IWA/UNEP. Beacon Press, London.

Jonker, 2002 L. Jonker, Integrated water resources management: theory, practice, cases, Physics and Chemistry of the Earth 27 (2002), pp. 719-720. SummaryPlus | $\underline{\text { Full Text + Links }}|\underline{\text { PDF (41 K) }}| \underline{\text { Abstract + References in Scopus } \mid \text { Cited By in }}$ $\underline{\text { Scopus }}$

Lomborg, 1998 B. Lomborg, The Sceptical Environmentalist, Cambridge University Press, Cambridge (1998).

MORI, 2002 MORI, The 2004 Periodic Review: Research into Customer's Views (2002).

Norton and Steinemann, 2001 B.G. Norton and A.C. Steinemann, Environmental values and adaptive management, Environmental Values 10 (2001), pp. 473-506.

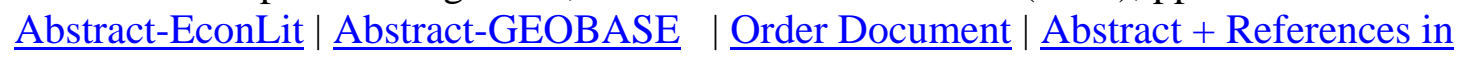
$\underline{\text { Scopus }}$ | Cited By in Scopus

O'Connor, 2002 D. O'Connor, The Walkerton Inquiry: the Events of May 2000 and Related Issues. Part One, Queen's Printer for Ontario, Toronto (2002).

Ohlsson, 1999 L. Ohlsson, Environment, Scarcity and Conflict—a Study of Malthusian Concerns, Department of Peace and Development Research, Gotebourg University, Gotebourg (1999). 
Postel, 1992 S.L. Postel, The Last Oasis, Earthscan, London (1992).

Rawls, 1999 J. Rawls, A Theory of Justice, Belknap Press, London (1999).

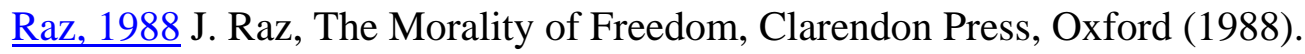

Rhodes, 1997 R.A.W. Rhodes, Understanding Governance, Open University Press, Buckingham (1997).

Richardson et al., 1992 J.J. Richardson, W.A. Maloney and W. Rudig, The dynamics of policy change: lobbying and water privatisation, Public Administration 70 (1992), pp. 157-175. Abstract-GEOBASE | Order Document | Abstract + References in $\underline{\text { Scopus } \mid \text { Cited By in Scopus }}$

Rousseau, 1994 J.J. Rousseau, Discourse on Political Economy and the Social Contract, Oxford University Press, Oxford (1994).

Scharpf, 1999 F. Scharpf, Governing in Europe: Effective and Democratic?, Oxford University Press, Oxford (1999).

Schimmelfennig, 1996 F. Schimmelfennig, Legitimate Rule in the European Union: the Academic Debate, Tubingen Working Paper vol. 27 (1996).

Snider, 2004 Laureen L. Snider, Resisting neo-liberalism: the poisoned water disaster in Walkerton, Ontario, Social and Legal Studies 13 (2004) (2), pp. 265-289. Full

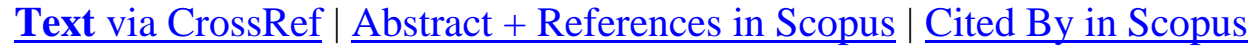

Stikker, 1998 A. Stikker, Water today and tomorrow; prospects for overcoming scarcity, Futures 30 (1998) (1), pp. 43-62. Abstract | PDF (1237 K) | Abstract + References in Scopus $\mid$ Cited By in Scopus

Strang, 2001 V. Strang, Evaluating Water: Cultural Beliefs and Values about Water Quality, Use and Conservation, Water UK, London (2001).

Summerton, 1998 N. Summerton, The British way in water, Water Policy 1 (1998), pp. 45-65. SummaryPlus | Full Text + Links | PDF (241 K)

Turner et al., 2005 A. Turner, S. White, K. Beatty and A. Gregory, Results of the largest residential demand management program in Australia, Water Supply 5 (2005) (3-4), pp. 249-256. Abstract-EMBASE | Abstract-GEOBASE | Order Document | $\underline{\text { Abstract }+ \text { References in Scopus } \mid \text { Cited By in Scopus }}$

Westcoat, 1992 Westcoat, J.L., 1992. Book review of Mitchell, B., (ed.). 1990. Integrated Water Management: International Experiences and Perspectives. London: Belhaven Press. Global Environmental Change. March. 70-71.

Winpenny, 1994 J. Winpenny, Managing Water as an Economic Resource, Routledge, London (1994). 
${ }^{1}$ The United Nations utilises Malin Falkenmark's 'Water Stress Index' to classify water stress as reached when annual renewable freshwater supplies drop below $1700 \mathrm{~m}^{3}$ per person. When this figure drops to below $1000 \mathrm{~m}^{3}$ per person the population is deemed to face water scarcity (Falkenmark and Widstrand, 1992 and Stikker, 1998). Critics of the Water Stress Index argue that this gross accounting for national water budgets disguises regional disparities (Postel, 1992) and may not include environmental concerns in the distribution of water resources (Global Water Partnership, 1996). Whilst water stress can be caused or exacerbated by natural phenomena and global warming (Herrington, 1998, Arnell, 1998 and Lomborg, 1998) it can also be the result of structural problems in which supply from the resource to the user is erratic, low-quality or insufficient (Lomborg, 1998 and Winpenny, 1994). Falkenmark has further refined her definition to highlight the disparity between 'blue' water and 'green' water resources. Solutions to water stress can then lie within the realm of efficient management.

$\stackrel{2}{ }$ Crudely, adaptive capacity details the way in which individuals, organisations and economic sectors develop and retain the ability to adjust to changing circumstances. $\underline{3}$ Other hallmarks, or modes, of good governance include accountability, transparency, efficiency and effectiveness. For further reference see Rhodes (1997). ${ }^{4}$ An option space is the set of choices that decision makers select from. Often the actual option space does not map directly onto the perceived option space of the decision maker. Option spaces are also malleable. Policy goals can be achieved both by widening option spaces and by modifying conceptual spaces to match.

${ }^{5}$ Arguably, in liberal theory legitimacy receives three somewhat different kinds of emphasis. This thesis can be exemplified by reference to pervasive themes in legal and political though. There is insufficient space within this paper to thoroughly critique the various models of legitimacy, but, what can be suggested is that different models of legitimacy can be seen as privileging (i) freedom, (ii) functionalism, and (iii) integration. Legitimacy as freedom, or autonomy, is initially found in the work of Hobbes (1996) - legitimacy as the passing up of some individual freedom for a greater collective freedom is also explored in Rousseau's (1994) notion of the 'social contract' and articulated more recently in the work of John Rawls (1999). Legitimacy is viewed by these contributions as a conduit to create constitutional stability which then develops into a shared social consensus. Legitimacy can also be seen as functional. The work of Joseph Raz (1988) is exemplary in this context. Legitimacy is depicted as enabling; providing a consensual mediation between citizen desires and the limits of practical authority. Legitimacy as integration can be found in the work of Ronald Dworkin (1996) who places legitimacy firmly within a notion creating an integrated social structure of rights and principles.

${ }^{6}$ Opposition included bad press from the national media (Haughton, 1998), a rebellion in parliament (Richardson et al., 1992) and negative results from public opinion polls (MORI, 2002). 